\title{
ARTE-EDUCAÇÃO, ÉTICA E ESTÉTICA ${ }^{1}$
}

\section{O resgate da expressividade, do lúdico e da criatividade da criança, através da Arte-Educação, no espaço escolar}

O tema é amplo, porque valeria rediscutir a escola e suas propostas educacionais como um todo.

É bastante freqüente que pessoas de diferentes espaços sociais - muitas vezes de campos profissionais e intelectuais nos quais têm reconhecidas suas capacidades e competências -, quando o tema da arte na escola é abordado, respondam:

- de arte para crianças eu não entendo nada!

- em arte eu sou um ignorante!

- de teatro e música eu não entendo, nem sei se gosto!

- eu sou uma negação para escrever, pintar ou cantar!

- meus pés são de chumbo!

Esta última bela metáfora serve como confissão pública da incapacidade de expressar-se ou relacionar-se com os outros, principalmente com crianças. É evidente que não está clara a percepção de que as pessoas se alimentam e se desenvolvem com a arte. Isso só acontecerá quando abrirmos todas as comportas que represam as linguagens da comunicação. A escola não basta como espaço recriador de experiências e informações estéticas se, ao mesmo tempo, não existir a possibilidade de se elaborar, junto às técnicas e às práticas artísticas, os sentimentos e a emoção de cada aluno.
Formação e informação, sem dúvida, deverão acontecer através de vivências, no mesmo fazer. Mas para que isso aconteça, a educação (nas escolas) terá de abrir as portas da afetividade. Afetividades que, quando não ocorrem, tornam impossíveis que se experimentem profundamente e, com liberdade, as expressões em cores, palavras, sons, danças, histórias, invenções e criações imaginárias que constituem a matéria-prima utilizada individualmente, mas que também precisa ser compartilhada nas expressões coletivas.

A escola é frágil em sensibilidades compartilhadas; frágil e autoritária ao mesmo tempo... (Quem manda aqui sou eu!)

O lar é bastante semelhante: organizado, muitas vezes, maquiando contrastes e conflitos sociais difíceis de assimilar, deixando lastros de preconceito e medo.

A arte e a expressão precisam de espaços mais largos, menos organizados e disciplinados. Aulas de experimentação, projetos e conteúdos que resgatem e dêem vida a rituais coletivos nos quais a imaginação, as sensibilidades artísticas, as identidades aconteçam fora das programações competi-

\section{O AUTOR}

\section{Ilo Krugli}

Arte-educador, autor, diretor e coordenador de cursos do Teatro Vento Forte.

1. Originalmente publicado na revista E - SESC. São Paulo: SESC-SP, n.1, ano 3, julho de 1996. p. 33-34. 
tivas ou dos festejos estereotipados do consumo, dos calendários cívicos e comerciais em que a criatividade e a arte são programadas nas agências publicitárias e nos escritórios gerenciais dos shoppings.

Falando de todos os espaços autoritários e manipuladores, queremos expressar que acreditamos numa transformação dos seres através de um projeto de educação no qual a liberdade de criação surja dos próprios jogos de expressão e dos espaços concretos e subjetivos, os quais permitam o renascimento de um ser mais livre e integrado. Através da arte propõe-se reconstruir uma arquitetura social, ética e, sobretudo, estética.

\section{EXPERIÊNCIAS LÚDICAS}

Durante vários anos trabalhamos um processo e um conteúdo temático que chamamos de $O$ quintal, o espaço esquecido. Não se tratava apenas dos míticos espaços saudosistas da aldeia, do fundo do quintal, da praça, da rua, sem dúvida cada vez mais urbanos. Tentávamos mostrar a necessidade de vivenciar espaços anárquicos, como o quintal, onde se despejam objetos, não mais necessários, quebrados ou outros que faziam parte de um universo menos organizado, com uma outra utilidade; e onde se podia experimentar organização e caos, experiências impossíveis em sala de aula ou dentro de casa. O imaginário e a responsabilidade desdobrando-se talvez como um grande teatro, construtivo ou destrutivo, muitas vezes transgressor - jogos emocionais em que as simbolizações vão dos materiais com que se brinca à própria ação física. $\mathrm{E}$, enquanto símbolos, não só apenas aqueles que expressam sentimentos internos, escuros ou mais ou menos catárticos, mas também aqueles que representam expressões concretas da individualidade e das diferentes formas de percepção das realidades humanas.

Existe em cada criança (cada ser) características psicológicas, sensibilidades instintivas, as quais poderíamos chamar de instinto estético, assim como chamamos de instinto a sexualidade e o desejo de sobrevivência. Estas diferenças e singularidades também dão forma estética à expressão, mas isso exige um caminho desreprimido enquanto modelos, estereótipos, pressões para que se integre ao mundo encantado dos adultos.

Hoje há dois tipos de escolas no país: as do Estado e as privadas. Possivelmente nestas últimas tenta-se, através da arte, configurar uma qualidade de formação apesar de, às vezes, também ficar no modelo; sobretudo porque os pais, muito mais que nas escolas do Estado, exigem preparação para que se integre a criança numa elite social, cultural, econômica etc. Mas, tanto uma escola quanto a outra ainda não têm em seu horizonte preparar seres com maturidade, liberdade e capacidade de escolha de vida.

Lembro-me de que, nos anos 60 , nosso mestre Augusto Rodriguez rejeitava a importância de se levar as crianças aos museus. Nós não pensamos da mesma forma, porque achamos que os museus têm e vão ter de mudar, igualmente o teatro (nossa luta de anos) também tem que se transformar muito, assim como todos os produtos culturais para crianças e jovens.

Não me incomodo que existam correntes de Arte-educadores que trabalham slides de artistas como Picasso, Chagall ou outros maravilhosos, criando outras identidades, no sentido de desenvolver a imagem da criança. Mas temos que prestar atenção ao que destacamos, ao que ficamos atentos, ao que sacralizamos; como também para os es- 


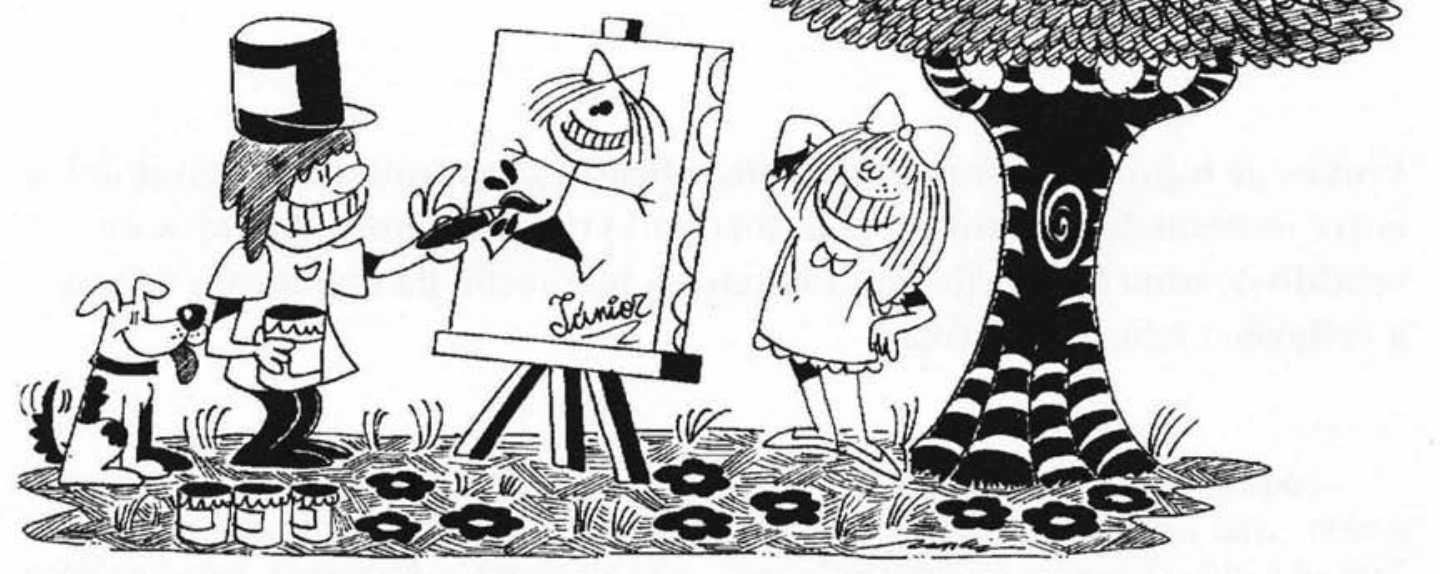

paços esquecidos e essenciais onde as identidades emocionais e psicológicas têm contato com o mito e o sonho, o instinto estético essencial, onde existe o rio fluente da História coletiva do ser humano.

Realizamos experiências coletivas de expressão, integrando várias linguagens, todas codificadas com bastante liberdade, determinando ao professor e ao animador os papéis de integrador e estimulador, respectivamente, da expressão festa. Acontecimento em espaços abertos, com uma grande oportunidade de desenvolver experiências nas

Resumo: $\mathrm{O}$ autor discute a necessidade de a escola resgatar, através da disciplina ArteEducação, além das técnicas e práticas artísticas, o exercício da expressividade e da emoção da criança. Salienta a oportunidade de projetos que resgatem e dêem vida à experimentação nas quais a imaginação, a sensibilidade e a identidade aconteçam fora de programações competitivas e estereotipadas.

Palavras-chave: Arte-Educação, emoção, sensibilidade, experiência lúdica quais o prazer se soma às outras expressões: oportunidade para o resgate da festa.

Sabemos que a formação do professor nem sempre, ou poucas vezes, habilita-o para experiências semelhantes. Mas, de qualquer forma, acreditamos que, se as escolas abrirem um projeto mais integrado com a comunidade, os professores serão obrigados a encontrar caminhos criativos, que não eliminam a experimentação e a conquista desta linguagem da comunicação.

A arte popular e os artistas populares podem contribuir ricamente para esse projeto.

Abstract: The author discusses the need for the school to make resurface, through the Art-Education discipline, over and beyond the artistic techniques and practices, the child's exercise of expressivity and emotion. It stresses the opportunities brought on by projects that bring back and give life to experimentation and in which imagination, sensibility and identity take place outside of competitive and stereotyped programs.

Key words: Art-Education, emotion, sensibility, ludic experience 